\title{
THE ROLE OF EDUCATIONAL TECHNOLOGY IN THE EFFECTIVE LEARNING AND TEACHING IN THE SCHOOLS AND COLLEGES IN NIGERIA
}

\author{
by \\ A. K. Yusuf \\ Faculty of Education, \\ University of Sokoto, Nigeria.
}

\begin{abstract}
This paper outlines briefly, some views of the term "Educational Technology" and its role generally in the field of education as evident from research findings. The urgent need for lowcost educational technology for schools and colleges in Nigeria is discussed. Attention is also drawn to the need to re-orient the teacher to his task, if new methods and media are to be used successfully. Finally, it is further suggested that future use of the achieved methods and media may differ radically depending among other things on the objectives to be achieved and the entry behaviour of the students, particularly when we employ the low-cost educational technology for effective learning and teaching. The importance of an Educational Resource Centre, and Teachers' Resource Centre are among other things strongly suggested.
\end{abstract}

\section{INTRODUCTION}

Learning is a continuous process. Everyday we learn new things. Knowledge is expanding at a geometrical rate as new ideas, techniques and instructional materials to mention a few are being developed. But what is crucial to us, I think, is the way in which we can impart the present knowledge to the child in a manner such that even after leaving school, he or she keeps in touch with the expanding knowledge that is useful to the child's mental, physical, social and spiritual development with minimum cost. Efforts toward attaining the above goal by educationists, philanthropist, state and the federal government are commendable. However, a new discipline is born which addresses itself to producing a wholesome individual through efficient communication of knowledge. It is called Educational Technology. The question then is, what is Educational Technology? How useful is it in the educational circle? How do we make it effective in our teaching and learning process? The next few pages will attempt answers to the questions raised. 


\subsection{Views on the Meaning of Educational Technology}

"Many attempts have been made to define educational technology, but with very little success" (Morrie, 1975). In the initial report of the National Council for Education Technology, NCET (1969) it states:

\footnotetext{
the term 'Educational Technology' since it is relatively new, is in its nature clusive, it means different things to different people. To some, it is no more than a fashionable synonym for-audio-visual alds. To others it has a wider connotation, implying an attempt to rationalise the whole structure of education and training in terms of improved methods of allocating and using both human and physical resources. To others again it carries a portent of mechanical futures to be dreamed of and then guarded against. Others still, conscious of our limited state of knowledge of the complexities of human learning deny that there can yet be any genuine technology of education and training.
}

In their view, education is destined to remain in a pre-technology era until a solid basis of theory has evolved from which scientific applications can be derived.

Much of the confusion that surrounds educational technology is derived from the ambiguity of its definition. The numerous definitions confuse the teacher and the student and frustrate his ability to understand as well as to evaluate. In the desire to avoid restricting educational technology to narrow limits, many of its interpreters give a broad sweeping definition. These comprehensive definitions include such terms as systems analysis, systematic approach, communications, media management design, evaluation and many others which are classed as jargon by some and accepted by others in educational circles. The search for a specific all-embracing definition causes some to divide educational technology into several components, the hardware and software approaches of Davies (1971), others, consider educational technology an area of curriculum development. In the words of Rowntree (1974). "Educational Technology is as wide as education itself".

Eraut (1972) itemises four distinct though inter-related areas of activity as a broader concept of Educational Technology in:

(i) the preparation and use of educational materials;

(ii) the application of knowledge about teaching and learning;

(iii) the planning, development and application of curricula;

(iv) the organisation of personnel, resources and teaching activities. 
It is some-what difficult for the layman to comprehend that the term educational technology should be open to such wide and varied interpretations. The definitions are broad and varied, including work in the fields of the pychology of learning, audio and visual methods of presentation, educational planning and organisation, curriculum development and course design, the production of teaching and learning materials, the storage, retrieval and dissemination of information, the allocation of resources, the costs and effectiveness of media in education, the design of learning spaces and the problems of innovation. The practical applications, however, are invariably quite narrow. When the term "educational technology" is used by many persons, what is usually meant is audio-visual or television. Audio-visual aids embrace many types of technology subsumed within this all-embracing and incorrect term audio-visual aids. There is a persistent effort on behalf of some organisations, such as Council for Educational Technology (CET), the Institute of Educational Technology at the Open Univeristy (IET OU), the Association for Educational and Training Technology (AETT), the work of Programme Learning Centres (PLC), to mention but a few, to broaden the definition to include everything from planning to postproject evaluation.

For the purpose of this paper, the definition of educational technology will be taken as the systematic application of scientific or other organised knowledge to the practical tasks of education and an educational technologist as one who seeks to understand the theory and to apply it. In short, a practical solution to all educational problems is the core objective of educational technology.

\section{Role of Educational Technology}

Armed with the various definitions/views on educational technology, it may now be useful to have a closer look at the role of educational technology in teacher education. Surely, the constant dynamic changes which characterise our educational system and in retrospect call for among other things newer methods, techniques, materials, restructuring of the content matter and in the organisation of subject evaluation in classroom situation are a great concern to every nation interested in educational development. Undoubtedly, the educational technology approach will play an important role in these changes as it offers purposeful suggestions on how best teachers can utilize their resources from the media and materials and how to arrange the condition of their use for optimum result.

Educational technology attempts to improve efficiency in education and to devise strategies for better teaching and more effective learning. New teaching 
strategies developed by the educational technology centres in Britain and United States of American include among others; Programme Learning Computer Assisted Instruction (CAI), Individualised Learning Simulation and Gaming all of which go a long way to make the teaching/learning process more feasible, practical, increasing labour specialization among teaching staff and making learning more responsive to the needs and aspirations of learners and the nation at large.

Educational Technology contributes immensely to academic studies in view of the fact that goals and objectives are always specified, ways of achieving such objectives outlined and various ways of evaluating and improving such studies drawn.

As Derek (1977) claimed in his article, educational technology can act as a unifying strategy in teacher education and training. For instance, it can make a significant contribution towards the professional or curriculum studies component of undergraduates or post-graduates. Educational technology is always called upon when any programme of this nature is being organized.

Educational technology invites one and indeed it forces one to be much clearer about the systems objectives and results, about the interdependence of its various components and about the relationship of its input and output. It helps to analyse problems in order to identify possible solutions. Educational technology has been used successfully in vastly different areas such as electric engineering, product design, military projects, ecology and education and training for which we are much concerned Romiszowski (1971).

\section{Research Evidence on the Role of Educational Technology}

Perhaps a few examples on the applications of educational technology to various aspects of education will suffice in order to throw more light on the role of educational technology.

Stoane (1980) has applied the principle of educational technology in a small project dealing with children who require special methods of education appropriate to the individual requirement. The result shows that a considerable improvement in learning abilities and in motivation was recorded.

Bedwell (1980) shows how one can equally apply the principle of educational technology to aid investigation and remediation of the under achieving child. The approach led to achieving the expected rate of progress with consequent saving of time and frustration.

Hills (1980) gave an account of how educational technology can be used to help the unemployed. He gave the example of City and Guilds of London In- 
stitute and Management Services Commission.

Nevile (1977), Beach (1980) and Romíszowski (1981) have described the application of educational technology to course planning at Open University and other training in the military and normal University Institutions. Examples are given of United Kingdom Open University and the University of Birmingham.

In another development, Oakely (1977), has equally described the application of educational technology to the design of courses offered at the North East London Polytechnic. It was applied to the following courses:

1. A bachelor of education degree course for serving teachers.

2. A graduate certificate in education.

The same educational technology approach was applied in the design of inservice courses in education at the University College Cardiff, Wales.

Hurlow (1980) who later researched into the effectiveness of the programme came out with positive results as respondents are very satisfied with the course content, objectives and the outcome of the evaluated course work.

The discussion thus far, centres around the significance and role of educational technology, the basic premise of which is the practical application to solving educational problems. What are some of these problems?

\section{The Problematic Areas}

Right from the word go, it is imperative to state that the formal education as it is administered in most of our schools today, is alien to our culture and traditions. A lot of problems were created by the borrowed formal education programme for instance, some of the rigid rules and regulations of our educational system have produced passive, mechanical and 'efficient' government servants who try to play safe. A large proportion of our students drop out of each grade and each terminal, especially the primary and secondary school leavers. A large number of our uneducated or educated youths are unemployed, underemployed or unemployable. The growing population of students, renders a large majority of teachers to the lecture type of verbal and theoretical teaching supported by copious notes which the pupils are forced to memorize. Here, only the first level of the educational objectives (recall) is exercised. These shortcomings amongst many others are not in the best interest of nation building, and an obstacle to the National Policy of Education (NPE) and the Harare Declaration (HD).

Even though the concept of educational technology is as old as the name itself, it gained currency in our country because of the sad situation mentioned above and it gives the sadly lacking practical application to solving our educa- 
tional problems.

We should therefore, look at educational technology as an integral part of the teaching-learning process which will be invaluable in teaching for understanding in our new 6-3-3-4 Educational Policy. Students of all ages in all disciplines and of course at all levels, learn better by doing. It is only through the hands, that the heart and mind could be educated. Since it is only what you do, or participate in physically and mentally that you remember. Our task as teachers therefore, is to find ways by which we can utilize the environment to aid the teaching and learning process. Education as from Primary and Secondary levels, and even tertiary must become TECHNOLOGICAL, PRACTICAL and MANUAL at the same time. If the so-called general education is to become truly general, educational technology must be developed; because while in action, it makes the teaching-learning situation more active, lively, intelligible with meaning and purpose.

It is a well known fact that instructional materials are being developed and modernized all the time. Internationally manufactured educational technology materials including electrical and electronic gadgets like recorders, film projects, video recorders, television, teaching machines, computers and language laboratory to mention a few, are available. I must state that I am not unaware of the value of these equipments for specialized training of personnel, enrichment and for widening general knowledge. However, apart from the fact that they are expensive and difficult to maintain and taking cognisance of the existing economic realities in this country, the costly materials and the realities of our social settings like constant power failures and lack of enough qualified technical manpower facing the country, render the gadgets underproductive. No wonder, some of these electronic gadgets are lying unused and gathering dust in some institutions in our country.

Faced with these realities, we need an improvised educational technology apparatus from discarded materials and what are available in nature which could be transformed to effective teaching in the classroom. Happily enough, we have these in abundance, very cheap to produce and of real value. This exactly is the gospel the author is preaching.

Such educational technology materials which can be extracted from the environment and which will be of educational value include pictures; flash cards, posters, charts, diagrams, maps, graphs, picture books, exhibits, flannel boards, mock-ups, objects, models, blackboard or chalkboards, bulletin boards, pegboards; audio-visual kits, displays and exhibitions and programme learning materials. These low-cost teaching materials are effective for teaching and learning. 
If properly used they can make a significant contribution in reinforcing the role of textbooks, oral instruction and exercises. Since seeing, hearing, touching, smelling and manipulating things are involved, it strengthens and enrichs the child's perception, stimulates senses and promotes self-activity in children, arousing their curiosity, stimulating inquiry and skills in observation which are the bases of learning. It is gratifying that the government itself is aware of the unique role such low-cost educational technology materials offer in effective teaching and learning. The annual symposium held in Ibadan in April, 1983 on "Educational Technology in Action", is a living testimony. At this symposium, an adhoc committee was set up to plan and organise a National Workshop on locally produced teaching aid/materials in Nigeria. A Workshop had been organized and sponsored jointly by the NTI Kaduna and The Federal Ministry of Science and Technology in which school materials like writing materials, the educational board, and other teaching aids were produced. A participant, for instance, showed how to design an incubator using locally produced materials with $75 \%$ success, while another participant demonstrated the procedure in producing chalk locally. These, I think are laudable innovations which we as teachers should address ourselves to.

That being said, we need to ask ourselves one other question, how can we produce these materials, and effectively use them in the classroom? In answering this question, let me start by saying that there are two important levels at which decisions about the use of instructional materials in education should be made:

1. The level of design and production

2. The level of implementation and use (Agun 1982).

First, there is need to establish clear guidelines for the selection of materials. The educational and instructional objectives of the materials must be ascertained. The characteristics of the learning for which the materials are originally designed and produced should be identified. The usefulness of the content of the materials is to be ascertained in terms of the educational objectives to be achieved and in terms of the characteristics of the learning, and their entry behaviour.

The approach of the author of producer of materials must be critically examined. The coverage of the subject matter and the organisation of the content to facilitate learning are also important factors to be considered.

Sometimes there is the need to be concerned with the physical features of instructional materials. Factors like clarity, attractiveness, durability, size, weight of materials for ease of handling and storage should be considered.

In the area of production, apart from specific practical techniques for producing each of the various types of materials, the following general guideliness can be followed: 
a. Select specific instructional objectives, which will be guided by the overall curriculum objectives.

b. Next is to identify the characteristics of learners with or for whom the materials will be used.

c. Select the content of the message that the material will carry: which of course will be related to the objectives.

d. Select the appropriate medium for presenting the message. A combination of media may sometimes be used. The medium may be simple charts, posters, pictures, diagrams or even the chalkboard.

e. Determine the cost

f. Design and develop the materials

g. Produce the materials observing closely, the rule of clarity, simplicity, accuracy, durability and managability.

h. Test the materials for effectiveness. You may pre-test with sample population. Feed-back from such try-out could be helpful in pointing out areas of weakness i.e. inaccuracy, complexity and ambiguity.

The writer has other suggestions to make in ensuring appropriate and effective use of low-cost educational technology materials.

(1) There is the need to establish as a matter of urgency, Resource Centres in each of the State capitals with tentacles in each local government area. The aim and objectives of such centres should be to produce, and retrive materials. Production of materials and training facilities should be included. To effect this, we need well experienced librarians and technicians including teachers. A Resource Centre briefly put is a place where a wide and varity of education materials and equipment or information carriers are stored.

(2) Apart from resource centres, the writer believes there is a need for teacher centres all over the local governments in Nigeria. This will help teachers to grow steadily on their job. They should be centres where teachers meet to exchange ideas, share their views, problems, experiences and acquire basic skills in producing instructional materials which can serve many schools in their localities. (3) It is further suggested that a committee be formed which will direct the affairs of producing low-cost educational technology materials. Validating and recommending ways of improvement should be the prime objectives.

(4) Workshops, seminars, symposia, specifically aimed at improving the lowcost production of materials should always be organised at regular intervals both at local, state and the Federal Government levels like the "National Task Force on Low-Cost Educational Technology"'.

(5) One way of ensuring appropriate and effective use of low cost instructional materials in education is to expose teachers, teachers in training to courses in the design and production of materials. The courses should help the 
teachers not only to acquire the basic skills and knowledge in the planning, design and production of materials, but also to develop favourable attitudes towards the use of materials as part of their regular teaching functions. This can be done through in-service and or on the job training.

(6) The impact of Educational Technology should be felt in every stage of the educational ladder. Introducing the concept somewhere in the middle or later stages of the educational hierarchy will not and cannot take roots nor produce the desired results. As a matter of priority, it is suggested that the concept of Educational Technology ought to be introduced here and now as a core subject in our teachers colleges of education, and Universities in Nigeria; where aspects of educational technology like production methods; design; evaluation; and preparation of certain instructional aids will be taught at least in teachers colleges. As for higher institutions, the writer suggests a degree programme in educational technology and or certificate or diploma course in educational technology. (A proposal by the author as to what should constitute the content of a certicate/diploma course in educational technology is attached as Appen$\operatorname{dix}$ A).

(7) Finally, to make the whole exercise effective, all schools, colleges, universities, and colleges of technology must work hand in hand, to share their experiences and disseminate such experiences to reach the humble teacher in the classroom.

\section{Conclusion}

The role of educational technology as a faciliator of the achievement of educational objectives, and innovations has been recognized. The author has endeavoured from the foregoing pages to give ideas on how a modest, low-cost material could be of immense value to a re-surgent nation in its educational technology efforts. While one is aware of the limitations of this laudable programme, efforts should go on in areas of innovations to pull our resources together, share our experiences in making better teaching, development, wholesome individuals and the nation. Let us therefore, turn every difficulty and problem into an opportunity and challenge. 


\section{APPENDIX A \\ SOME IMPORTANT TOPICS TO BE INCLUDED IN THE \\ CERTIFICATE/DIPLOMA COURSE IN EDUCATIONAL TECHNOLOGY}

Aim of the Courses

The course should be designed to enable teachers and lecturers to demonstrate effectively both the teaching strategies and instructional media in their own teaching and to equip them with the necessary theoretical knowledge and practical experiences in various aspects of teaching and learning.

\section{Duration}

This will depend on the objectives, the entry behaviour of the learner, and content to be taught. However, it should not be less than three months and a maximum of two years is recommended.

\section{Objectives of such Courses}

The role of such course can be summarised as to help the teacher acquire skills in:

(i) Understanding the explicit or implicit aims in which they work, of learning materials which they are required to use and of syllabuses which they are asked to follow

(ii) Formulating and selecting learning objectives

(iii) Selecting means to achieve learning objectives

(iv) Developing learning materials to achieve objectives

(v) Assessing and monitoring pupil progress and evaluating their parts of the learning systems they (the teacher) control

(vi) Managing a learning objective

\section{Content} sion:

In line with the above stated objectives, the underlisted topics will be appropriate for inclu-

1. The psychology of learning and teaching

2. Writing Course aims and objectives 
3. Courses designs and systems planning

4. Practical skills associated with the production of resources materials

5. Management skills in education, particularly those associated with the management of innovation

6. Designing learning packages

7. Techniques in assessment and evaluation of learning/teaching strategies and media

8. Teaching and classrooms management skills.

\section{REFERENCES}

1. Agun, L.. (1982) 'The Place of Instructional Materials in Curriculum Development". A paper presented to NERC Lagos.

2. Beach, D.M. (1980) “Utilizing Educational Technology in Teacher Training” in Educational Technology to the Year 2000. Kegan Page, London, Pp. 176 - 177.

3. Bedwell, C.H. (1980) "The application of Technology to aid the investigation and remediation of under-achieving child" in Educational Technology to the Year 2000 Kegan Page, London Pp. $72-95$.

4. Davies, K.G. et al "Colleges of Education Learning Programmes: A Proposal”. Working Paper 5. NCET Councils and Education Press, London.

5. Davies, I.K. (1971) The Management of Learning McGraw Hill, London.

6. Embling, J.H. (1976) "The Schools and Educational Technology" in Instructional Year Book of Educational and Instructional Technology. Kegan Page, London, Pp. 1 - 5.

7. Eraut, M. (1972) “In-service Education for Innovation". Occasional Paper No. 4NCET. Councils Press, London.

8. Gass, J.R. (1971) Educational Technology - In The Design, Implementation of Learning Systems: Council For Educational Press, London.

9. Hills. J.E. (1980) "Educational Technology Helps The Unemployed" in Educational Technology to The Year 2000. Kegan Page. London, Pp. $34-36$.

10. Hurlow, A. (1978) "An Investigation into the Outcomes of the B.Ed. Programme University College, Cardiff”' Ph.D. Thesis Unpublished.

11. Mackenzie, N. (1970) Editorial: Journal of Educational Technology, 1. Councils and Education Press, Londøn.

12. Morris, J.G. (1975) "The Use Made of Educational Technology in the Education Systems" in Journal of Edukation Television, No. 2 Council Press, London.

13. NCET (1969) "Toward more Effective Learning in the Report of the National Council for Educational Technology. (NCET). Councils and Education Press, London.

14. Nevillie, C. (1977) "The Role of Educational Technology in teacher Education". In The Role of Education Technology in Teacher Education. CET. London. Pp. 9-15.

15. Oakley, J. (1977) "Application of Educational Technology in course Design" In the Role Educatianal Technology in Teacher Education. CET. London, Pp. 39-60. 
16. Romiszowski, A.J. “Designing Instructional Systems" Kegan Page, London.

17. Rowntree, D. (1974) Educational Technology in Curriculum Development. Harper and Row, London.

18. Strane, C. (1980) "Educational Technology in Special Education". In Educational Technology to the Year 2000. Kegan Page, London, Pp. 65 - 70.

19. Shankar, N. (1983) "Audio Visual Aids for pre-School and Primary School Children". A Paper presented to NERC Lagos.

20. Wood, A. (1979) “A Modular Systems of Self-Instruction in Educational Technology within a Course of Teacher Training". In Aspects of Educational Technology XIII. Kegan Page, London. 